\title{
Mahlep (Prunus mahaleb) meyvesinin kuruma kinetiği ve renk değişimi
}

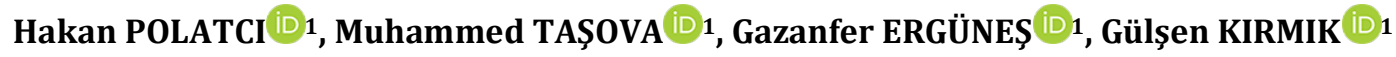 \\ ${ }^{1}$ Gaziosmanpaşa Üniversitesi Ziraat Fakültesi Biyosistem Mühendisliği, Tokat
}

\section{Öz}

Dış kabuk yapısının oldukça ince olması bünyesindeki nemin dışarıya kolay bir șekilde çıkmasına sebep olmakta ve kullanım anına kadar bozulmadan saklanması zorlaşmaktadır. $\mathrm{Bu}$ çalışmada, mahlep meyvesi etüv ve mikrodalga kurutucuda kurutularak kuruma modelleri ve renk kalitesi belirlenmiştir. En uzun kurutma işleminin 93 saat ile gölge ortamında ve en kısa kurutma işleminin ise 42.5 dakika ile mikrodalga kurutma yönteminde olduğu tespit edilmiştir. En uygun ince tabakalı kuruma modelinin belirlenmesi için alınabilir nem oranı değerleri 5 farklı eşitlikte işlenerek, tüm model ve yöntemler arasında Alibaş ve Wang Sing modellerinin en uygun olduğu bulunmuştur. Mikrodalga kurutma yönteminde elde edilen verilerin diğer uygulamalara göre daha iyi olduğu istatistik analizler sonucunda belirlenmiştir. Çalışma sonucunda ortalama kuruma süresi ve renk değerleri açısından mahlep meyvesinin mikrodalga yönteminde kurutulmasının diğer yöntemlere göre daha uygun olduğu anlaşılmıştır.

Anahtar Kelimeler: Kurutma işlemi, son kalite özellikleri, kuruma parametreleri
Drying of mahaleb (Prunus mahaleb) fruit: drying kinetics and color change

\begin{abstract}
The extremely thin outer shell structure causes the moisture in the body to come out easily and it is difficult to store it intact until the moment of use. In this study, the most suitable method was determined in terms of drying models and color quality by drying mahaleb fruit in oven and microwave drying methods. It was found that the longest drying process was in the shade environment with 93 hours and the shortest drying process was in the microwave drying method with 42.5 minutes. In order to determine the most suitable thin-layer drying model, the available moisture content values were processed in 5 different equations and Alibas and Wang Sing models were found to be the most suitable among all models and methods. It has been determined that the data obtained in microwave drying method is better than other applications as a result of statistical analysis. As a result of the study, it was found that drying of mahaleb fruit in microwave method was more convenient than other methods in terms of average drying time and color values.
\end{abstract}

Key words: Drying process, last quality properties, drying parameters 


\section{Giriş}

İnsanoğlunun yerleşik hayata geçmesinden sonra, nüfusunun sürekli artmasıyla beraber sağllk ve beslenme konusu önemli bir hal almış ve bazı önemli bitki ve meyveleri tüketmeye başlamışlardır (Njume ve ark., 2009). Bu bitki ve meyve grubu, şu anki literatürde tıbbı ve/veya aromatik bitkiler olarak ifade edilmektedir. Başaran (2012), 1980 yllında Dünya Sağlık Örgütü tarafından bünyelerinde kimyasal-farmasötik maddeler sentezleyen, hastalıkları ve yaraları tedavi etmede etkin olan bitkiler tıbbi ve/veya aromatik bitkiler şeklinde tanımlamışlar. Araştırmalara göre yeryüzünde yaklaşık 20.000 kadar tıbbi ve aromatik bitkinin olduğu ve bunların gidalara koku, tat ve renk katması için kullanıldıkları belirtilmektedir. $\mathrm{Bu}$ meyvelerden birisi de mahleptir.

Mahlep meyvesi (Prunus mahaleb), gülgiller (Rosaceae) familyasından olup, çalı formda ve boyunun 8-10 m'ye kadar ulaştığı bilinmektedir. Kışın yaprağını döken ve yapraklarının ş̧ekli dairemsi ya da geniş yumurta biçiminde olan ve uzunluğu ise 3-6 cm'ye ulaşmaktadır (Anonim, 2018). Prunus mahalep ağacının uzunluğu ortalama 1 ile $5 \mathrm{~m}$ arasında değişmektedir. Dünya'da özellikle Batı Asya, Avrupa ve Asya'nın merkezlerinde ve Kuzey Afrika bölgelerinde bol miktarda yetişmektedir. Bunun yanında mahlep meyvesi hem taze olarak kendisi hem de mahlep tozu yapılarak Türkiye'nin ihracat ürünleri arasında yer alan önemli meyvelerden birisidir (Moghadam ve Khalighi, 2007; Blando ve ark., 2015).

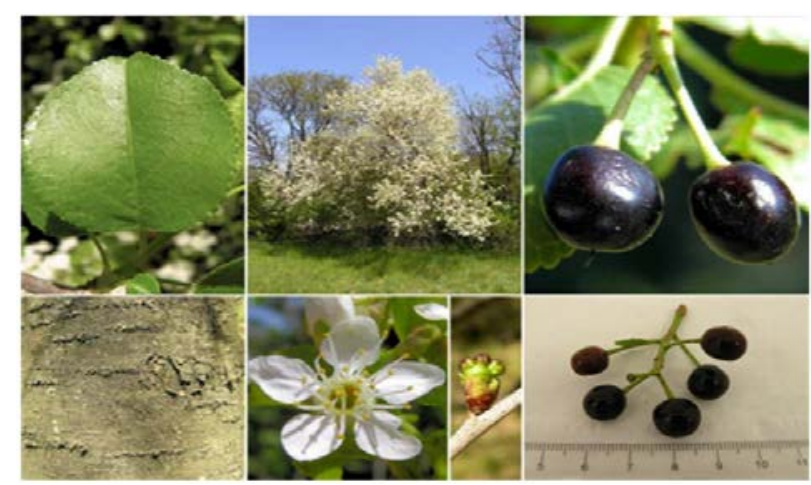

Şekil 1. Mahlep yaprağı, ağacı, meyvesi ve çiçeği (Blando ve ark., 2015).

Ülkemizde yoğunlukla Tokat, Mardin, Çorum, Amasya, Ordu, Erzurum, Uşak ve Van illerinde yetişmektedir. Mahlep ağacının isimleri bölge ve yörelere göre farklı adlarla bilinmektedir. Özellikle
Zile'de (Tokat) Endülüs, Tokat ve Amasya'da Mahlep veya Melhem, Merzifon'da (Amasya) ise idris ve pis ağaç olarak söylenmektedir (Aydın ve ark., 2002; Darıcı ve ark., 2016). Mahlep meyvesinin kullanım alanı olarak sağlık, gıda ve ilaç sanayisi başta olmak üzere birçok sektörde ihtiyaca göre farklı aksamları kullanılarak tüketilmektedir (Ieri ve ark., 2012; Öztürk ve ark., 2014).

Mahlep meyvesi olgunlaştıkça kabuk yapısı incelmekte ve bol sulu bir hal almaktadır. Bu durum hasat esnasında ve sonrasında önemli kayıplara neden olmaktadır. Özellikle kurutulduktan sonra kullanılacaksa bünyesindeki nem oranının bozulmadan depolanabileceği bir seviyeye kadar dürülmesi gerekmektedir. Bunun içinde uygulanacak kurutma yönteminin ve sıcaklığının iyi belirlenmesi gerekmektedir. Çünkü kurutma yöntemi ve sıcaklığ 1 ürünün fiziksel ve kimyasal birçok özelliğini etkilemektedir. Bu da ürünün kurutulduktan sonra kullanılacak alanlardaki ürünün kalitesini etkileyecektir.

Ürünlerin kurutulması için birçok kurutma yöntemi bulunmaktadır. Bunların başında ise geleneksel doğal kurutma yöntemi gelmektedir. Bu yöntem enerji ve iş gücü açısından oldukça avantajlı olduğu bilinmekle beraber, temiz olmayan son ürün ve uzun kuruma süresi gibi dezavantajları da vardır (Midilli ve Küçük, 2002; Göztok ve İçier, 2017). Yapay konvektif kurutma yöntemlerinde ise doğal kurutma yöntemlerindeki olumsuzluklar ortadan kalmakta, ancak enerji tüketimi değerleri açısından ise uygun bir yöntem değildir. Konvektif kurutma yöntemindeki bu olumsuz durumu ortadan kaldırmak, daha kısa sürede kuru ürün elde edebilmek için mikrodalga kurutucuların kullanımı son zamanlarda oldukça yaygınlaşmıştır. Mahlep püresiyle ilgili çalışmaların mevcut olduğu ancak meyvenin kendisiyle ilgili kurutma yöntemlerinin kalite ve kuruma kinetiklerine etkisinin araştırıldığ çalışmaların çok sınırlı olduğu görülmektedir. Literatürde, Duan ve ark. (2017; Alıç), Çelik ve ark. (2019; Karayemiş), Polatcı ve Taşova (2018; Yenidünya) karayemiş meyvesiyle benzer fiziksel özelliklere sahip ürünlerle kurutma çalışmaları yapılmıştır.

$\mathrm{Bu}$ çalışmanın amacı, mahlep meyvesinin farklı ortamlarda kurutularak kuruma süresi ile kuruma modeli ve renk kalitesi açısından uygun kurutma yönteminin belirlenmesidir. 


\section{Materyal Yöntem}

\section{Kurutma materyali}

Kurutma denemelerinde kullanılacak olan ürün, Tokat Gaziosmanpaşa Üniversitesi Ziraat Fakültesi bahçesinde yetişen mahlep ağacından toplanarak Biyosistem Mühendisliği Bölümü kurutma laboratuvarına getirilmiştir. Meyvenin sap kısımları alınmış, ezilmiş olanlar ayıklanmış ve kurutma işlemleri için hazırlanmıştır. Ürün kurutma öncesinde $+4 \pm 0.5^{\circ} \mathrm{C}$ sıcaklıkta buzdolabı ortamında saklanmıştır.

\section{Nem tayini}

Taze mahlep meyvelerinin başlangıç nem içeriğini belirlemek için ürün, kurutma dolabında $70{ }^{\circ} \mathrm{C}$ sıcaklıkta ağırlık değişimi sabitlenene kadar kurutulmuştur (Yağcioğlu, 1999).

\section{Kurutma yöntemi}

Ürünler etüvde, mikrodalga fırında, açıkta güneş ve gölge ortamlarda kurutulmuştur. Yöntemlerde kullanılan örnek miktarları etüv için $20 \pm 0.1 \mathrm{~g}$, mikrodalga için $15 \pm 1$ g ve açık ortamda yapılan kurutma işlemlerinde ise $45 \pm 1$ g mahlep kullanılmıştır. Kuruma esansında ağırlık değişimleri etüvde ilk başlarda 30' ar dakika sonra 1'er saat ve daha sonra da 2' şer saat aralıklarla tartılmıștır. Mikrodalga yönteminde de ilk başlarda $0.5^{\prime}$ er dakika sonra 1' er dakika ve daha sonra da 2' şer dakika aralıklarla ürünler tartımları gerçekleştirilmiştir. Güneş ve gölge kurutma işlemlerinde ise ilk başlarda 1' er saat sonra 2' şer saat ve daha sonra da 3' er saat aralıklarla kurutma materyallerinin ağırlık değișimleri tartılmıştır. Mahlebin en uygun kurutma sıcaklığı için literatürde herhangi bir bilgiye rastlanılmamıştır. Ancak Kaya ve Aydın (2008), çalışmalarında boyut ve genel biyokimya yapısı itibariyle mahlebe benzeyen karayemiş (taflan) meyvesini kuruturken $65{ }^{\circ} \mathrm{C}$ sicaklığl tercih etmişlerdir. Buna istinaden çalışmada, etüv kurutma yönteminde $65{ }^{\circ} \mathrm{C}$ kurutma havası sıcaklığ seçilirken, mikrodalga kurutucuda ise yapılan ön denemeler sonucunda $180 \mathrm{~W}$ güç değerinin uygun olduğu görülmüştür. Yapllan ön denemeler esnasında mahlep meyvesi önce 360 W güç değerinde 30 saniye çalıştırılarak kurutulmuş ve denemenin son aşamalarına doğru materyalin yandığı görülmüştür. Kurutucu içerisindeki ürünler belirli süre aralıklarında çıkartılıp $0.01 \mathrm{~g}$ hassasiyete sahip terazi ile tartılarak nem içeriği başlangıç ağırlığı dikkate alınarak \% 10-13 neme kadar kurutulmuştur. Günește kurutma sırasında ortalama sıcaklık $35{ }^{\circ} \mathrm{C}$ ve gölgede kurutmada ise ortalama ortam sıcaklığ $27^{\circ} \mathrm{C}$ olarak belirlenmiştir.

\section{Denemelerde kullanılan kurutucular}

Kurutma işlemlerinde kullanılan etüv kurutucu, Şimşek Laborteknik marka olup ST-120 tip modelidir. Kurutma havasının sıcaklığı üzerinde bulunan PID kontrol denetleyiciler kullanılarak kontrol edilmektedir. Mikrodalga kurutucu Vestel marka ve MD-GD23 model olup, toplamda $900 \mathrm{~W}$ güç çıkışı bulunmaktadır. Boyutları ise Yükseklik $\times$ Genişlik $\times$ Derinlik değerleri sırasıyla; $305 \mathrm{~mm} \times 508$ mm $\times 385$ mm'dir. Açıkta kurutmada kullanılan tel örgülü rafların ölçüleri ise $75 \times 75 \mathrm{~cm}$ olup, kalınlığı $3.5 \mathrm{~cm}$ 'dir (Şekil 2).

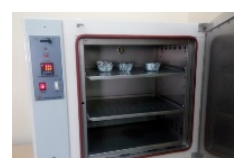

a

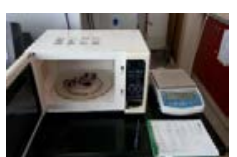

b



C
Şekil 2. Denemelerde kullanılan kurutma ortamları. a) Kurutma dolabı (etüv) b) Mikrodalga firın c) Açıta kurutma düzeni

\section{Renk analizi}

Deneme öncesi ve sonrasındaki mahlep meyvelerinin renk ölçümleri Minolta marka CR400 (Japonya) renk ölçerle yapılmıştır. Cihazda L, a, b renk değerleri ölçülmüştür.

(L), ürünün parlaklık değerini ifade etmekte ve 0100 arasında değişmektedir. L 0 (sıfır) değerini aldığında rengin siyah olduğunu yani yansımanın hiç olmadığını, L 100 değerini aldığında ise ürün renginin beyaz yani yansımanın tam olduğunu ifade etmektedir. (a) değeri, kırmızı - yeşil, (b) değeri ise sarı - mavi renkleri ifade ederken sirasıyla $(+,-)$ değerlerini almaktadır. Renk değerleri $\mathrm{a}=0$ ve $\mathrm{b}=0$ olduğu durumda ise rengin gri olduğunu göstermektedir (McGuire, 1992).

Ölçülen renk değerleri ( $L, a, b)$ kullanılarak; kroma $(C), h^{\circ}$, renk değişimi $(\Delta E)$, kırmızılık indeksi (a/b) ve kahverengileşme indeks (BI), değerleri de hesaplanmıştır. Hesaplanan renk kriterlerine ait eşitlikler Çizelge 1'de verilmiştir. 
Çizelge 1. Hesaplanan renk kriterleri

\begin{tabular}{cccc}
\hline Renk kriteri & Eșitlik & Referans & Eșitlik no \\
\hline Kroma & $C=\left(a^{2}+b^{2}\right)^{1 / 2}$ & Si ve ark. (2016) & $(1)$ \\
\hline Hue & $h^{\circ}=\tan ^{-1}\left(\frac{b}{a}\right)$ & Polatcı ve Taşova (2017) & $(2)$ \\
\hline Renk değişimi & $\sqrt{(L-L *)^{2}+(a-a *)^{2}+(b-b *)^{2}}$ & Dak ve ark. (2014) & $(3)$ \\
\hline Kırmızıllk indeksi & $a / b$ & Chen ve ark. (1997) & $(4)$ \\
\hline Kahverengileșme indeksi & $\mathrm{BI}=\frac{[100(x-0.31)]}{0.17}, x=\frac{a+(1.75 \times \mathrm{L})}{[(5.645 \mathrm{xL})+(a-(3.012 \times b))]}$ & Plou ve ark. (1999) & $(5)$ \\
\hline
\end{tabular}

\section{Kuruma modeli}

Kurutma materyalinin süreye bağlı ayrılabilen nem oranı değerleri 6 numaralı eșitlik kullanılarak hesaplanmıștır (Maskan, 2000).

$\mathrm{ANO}=\frac{M-M_{e}}{M_{0}-M_{e}}$

Burada;

ANO: Ayrılabilir nem oranı

M: Ürünün anlık nem içeriği (g)

$\mathrm{M}_{\mathrm{e}}$ Ürünün denge nemi (g)

$\mathrm{M}_{\mathrm{o}}$ Ürünün ilk nem içeriği (g)

Kuruma eğrilerini oluşturmak için literatürde yaygın olarak kullanılan Alibaș, Lewis, Page, Wang Sing ve Yağcıoğlu ince tabakalı matematiksel modelleri seçilmiştir. Eşitliklere ait modeller SigmaPlot 10. programinda regresyon analizi ile modeller oluşturulmuştur. Modellere ait eşitlikler Çizelge 2' de verilmiştir.

Çizelge 2. İnce tabakalı kuruma modelleri

\begin{tabular}{ccc}
\hline Model ismi & Eşitlik & Kaynak \\
\hline Alibaş & $\mathrm{MR}=\mathrm{k} \cdot \exp \left(\left(-\mathrm{h} . \mathrm{t}^{\mathrm{t}}\right)+(\mathrm{m} . \mathrm{t})\right)+\mathrm{n}$ & Alibaş (2012) \\
Lewis & $\mathrm{MR}=\exp (-\mathrm{k} . \mathrm{t})$ & Lewis (1921) \\
Page & $\mathrm{MR}=\exp (-\mathrm{h} .(\mathrm{t}))$ & Page (1949) \\
Wang Sing & $\mathrm{MR}=1+\mathrm{k} \cdot \mathrm{t}+\mathrm{h}^{2} \mathrm{t}^{2}$ & Wang ve Sing (1978) \\
Yağcioğlu & $\mathrm{MR}=\mathrm{k} \cdot \exp (-\mathrm{h} . \mathrm{t})+\mathrm{j}$ & Yağcioğlu (1999) \\
\hline
\end{tabular}

\section{İstatistik analiz}

Taze ve kurutulmuş mahlep örneklerine ait ölçülen renk değerleri SPPS 17. programında işlenerek frekans dağılımları ile tanımlayıcı istatistik analiz değerleri incelenmiștir. Ölçülen ve hesaplanan renk değerlerinin birbirleri arasında istatistiksel açıdan bir farkın olup olmadığı test etmek için Duncan çoklu karşılaştırma analizine tabi tutulmuştur. Ölçülen ve hesaplanan tüm renk değerlerinin birbirini etkileme dereceleri $(r)$ ve bunun önem seviyeleri $(p<0.01$ ve $p<0.05$ ) belirlemek için ise korelasyon (Pearson) analizi yapılmıștır.

\section{Bulgular ve Tartışma}

\section{Kuruma değerleri}

Meyvenin başlangıç nem içeriği \% 62.01 olarak belirlenmiş ve son nem değeri \% 10-13 aralığında olacak şekilde kurutulmuştur. Kurutma yöntemlerinde belirlenen materyale ait ortalama son nem oranları ile ortalama kuruma süreleri Çizelge 3' te verilmiştir.

Çizelge 3. Mahlep meyvesine ait ortalama kuruma performans değerleri

\begin{tabular}{cccc}
\hline $\begin{array}{c}\text { Kurutma } \\
\text { yöntemi }\end{array}$ & $\begin{array}{c}\text { Kurutma } \\
\text { șartı }\end{array}$ & $\begin{array}{c}\text { Ortalama son } \\
\text { nem (\%) }\end{array}$ & $\begin{array}{c}\text { Ortalama kuruma } \\
\text { süresi (dakika) }\end{array}$ \\
\hline Etüv & $65^{\circ} \mathrm{C}$ & 9.77 & 570 \\
Mikrodalga & $180 \mathrm{~W}$ & 11.51 & 42.50 \\
Güneș & $33^{\circ} \mathrm{C}$ & 10.72 & 2460 \\
Gölge & $27^{\circ} \mathrm{C}$ & 10.38 & 5580 \\
\hline
\end{tabular}

Tablo 3' e göre, kurutma yöntemlerinin ürünün kuruma karakteristiklerini etkilediği görülmektedir. Materyalin bünyesindeki mevcut nemin istenilen aralığa gölge ortamında ortalama 93 saatte ulaştığı ve aynı zamanda kurutma yöntemleri arasında en uzun işlem olarak da belirlenmiștir. En kısa süren kurutma işlemi ise mikrodalga kurutma yönteminde olduğu ve ortalama 0.7 saatte istenilen nem aralığına ulaştığı tespit edilmiştir. Literatürde mahlep meyvesine benzer ürünlerin yapıldığı kurutma çalışmalarında ise Güleç ve ark. (2017), mikrodalga, Infrared ve açıkta kurutma yöntemlerinde karayemiş kurutma çalışması yapmışlar ve ürünü istenilen nem seviyesine sirasiyla ortalama 25 dakika, 180 dakika ve 30 saatte ulaştığını belirlemişler. Altıok ve Otağ (2019), tüm ve dilimlenmiş kiraz örneklerini konvektif yönteminde 40,50 ve 60 으 sicaklarında kurutmuşlar ve ortalama kuruma sürelerini istenilen nem aralığına (\% 10) tüm kiraz meyvelerinde sirasıyla 60,50 ve 30 saatte, dilimlenmiş örneklerde ise sırasıyla 30, 20 ve 10 saatte istenilen nem aralığına düştüğünü tespit etmişler. Bantle ve ark. (2019), tatlı patatesi 20, 30 ve $40 \stackrel{\circ}{\circ}$ sicaklık değerlerinde kuruttuğunda sıcaklık değerlerinin kuruma sürelerini önemli seviyede etkilediği ve sıcaklık değerlerinin artmasıyla da kuruma süresinin belirgin oranlarda azaldığını ifade etmiştir. 


\section{Kuruma modellerine ait katsayılar}

Kurutulan mahlep örneklerinin kuruma süresine göre ayrılabilir nem oranlarını belirlemek için kuruma eğrileri oluşturulmuştur. Kuruma eğrilerine ait eşitlik katsayıları, regresyon denkleminin göreceli etkinliğini belirlemede kullanılan "belirleme katsayısı" ( $\mathrm{R}^{2}$ ) değerleri ve olasılık (p) değerleri etüvde kurutma yöntemi için Çizelge 4'de, mikrodalga yöntemi için de Çizelge 5'de verilmiştir. Buradaki $\mathrm{R}^{2}$ değerleri denemeler esnasında süreye bağlı ölçülen ağırlık değişimleri kullanılarak hesaplanan alınabilir nem oranı değerleri ile modellerin tahmin ettiği değerlerin, birbirlerine olan yakınlıklarını ifade etmektedir. Modellere ait $\mathrm{p}$ değerleri ise güvenli kullanım derecesi olan $p<0.05$ değerine karşılık denemelerde belirlenen değerleri göstermektedir.

Çizelge 4'e göre, etüv kurutma yönteminde elde edilen değerleri Alibaş ve Wang Sing ince tabakalı kuruma modelleri en iyi tahmin eden eşitlikler olarak belirlenmiştir.

Çizelge 4. Etüv yöntemi için matematiksel modellere ait değerleri

\begin{tabular}{|c|c|c|c|}
\hline Modeller & Katsayılar & $\mathrm{R}^{2}$ & $\mathrm{p}$ \\
\hline Alibaş & $\begin{array}{c}\text { k: } 0.9527 \\
\text { h: } 0.0018 \\
\mathrm{j}: 3.1500 \\
\text { m: }-0.2141 \\
\text { n: } 0.0454\end{array}$ & 0.9995 & $\mathrm{p}<0.0001$ \\
\hline Lewis & k: 0.0341 & 0.9503 & $\mathrm{p}<0.0001$ \\
\hline Page & $\begin{array}{l}\text { k: } 0.1880 \\
\text { h: } 1.1807\end{array}$ & 0.9979 & $\mathrm{p}<0.0001$ \\
\hline Wang Sing & $\begin{array}{l}\mathrm{k}:-0.1903 \\
\mathrm{~h}: 0.0096\end{array}$ & 0.9994 & $\mathrm{p}<0.0001$ \\
\hline Yağcıoğlu & $\begin{array}{l}\mathrm{k}: 1.1650 \\
\mathrm{~h}: 0.1851 \\
\mathrm{j}:-0.1586\end{array}$ & 0.9984 & $\mathrm{p}<0.0001$ \\
\hline
\end{tabular}

Çizelge 5. Mikrodalga yönteminde kullanılan matematiksel modellere ait değerler

\begin{tabular}{|c|c|c|c|}
\hline Modeller & Katsayılar & $\mathrm{R}^{2}$ & $\mathrm{p}$ \\
\hline Alibaş & $\begin{array}{c}\text { k: } 0.8535 \\
\text { h: } 0.0232 \\
\text { j: } 0.0005 \\
\text { m: }-0.1323 \\
\text { n: } 0.3542\end{array}$ & 0.7515 & $\mathrm{p}<0.05$ \\
\hline Lewis & $\mathrm{k}: 0.0341$ & 0.9503 & $\mathrm{p}<0.0001$ \\
\hline Page & $\begin{array}{l}\text { k: } 0.0093 \\
\text { h: } 1.4052\end{array}$ & 0.9758 & $\mathrm{p}<0.0001$ \\
\hline Wang Sing & $\begin{array}{l}\text { k: }-0.0214 \\
\mathrm{~h}:-9.9968\end{array}$ & 0.9939 & $\mathrm{p}<0.0001$ \\
\hline Yağcıoğlu & $\begin{array}{c}\mathrm{k}: 32.0437 \\
\mathrm{~h}: 0.0007 \\
\mathrm{j}:-31.0489\end{array}$ & 0.9939 & $\mathrm{p}<0.0001$ \\
\hline
\end{tabular}

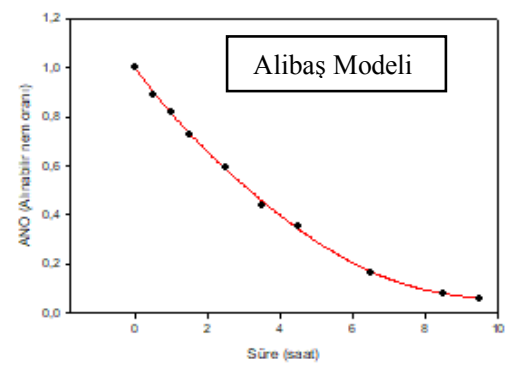

a) Alibaş modeli

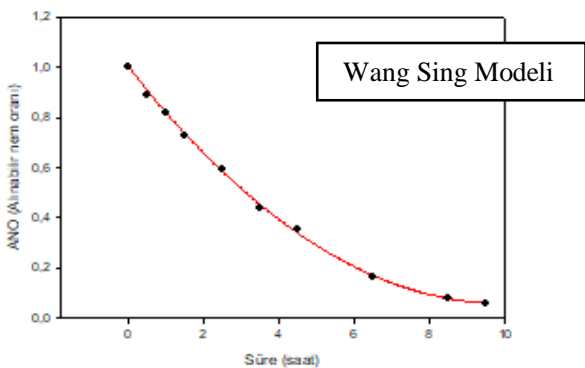

b) Wang-Sing modeli

Şekil 3. Tüm kurutma yöntemlerinde en iyi tahmin edilen matematiksel modeller 
Çizelge 5'e göre, mikrodalga kurutma yönteminde elde edilen değerleri Wang Sing ve Yağcioğlu ince tabakalı kuruma modelleri en iyi tahmin eden eşitlikler olarak tespit edilmiştir. Tüm kurutma yöntemleri arasında en yüksek $\mathrm{R}^{2}$ değerine sahip model etüv kurutucuda Alibaş ve Wang Sing modelleri olduğu tespit edilmiştir (Çizelge 3).

\section{Renk değerleri}

Taze ve kurutulmuş mahlep meyvelerine ait ölçülen $\mathrm{L}$, a ve $\mathrm{b}$ değerlerinin tanımlayıcı istatistik sonuçları Çizelge 6'da verilmiştir. Çizelge 6'ya göre, ortalama en yüksek parlaklık değerinin güneş kurutma yönteminde belirlenirken en düşük parlaklık değerinin ise etüv kurutma yönteminde belirlenmiştir. Ölçülen renk değerleri içerinde en büyük varyans değeri taze örneklerin parlaklık ve kırmızılık değerlerinde tespit edilirken, en küçük ise güneş kurutma yönteminde ölçülen sarılık değerlerinde tespit edilmiştir. Ölçülen parlaklık ve kırmızılık değerlerinin yığınlığı sadece gölge kurutma yönteminde sola tarafa yatık olduğu görülürken diğer yöntemlerde ise yine aynı değerlerin sağ tarafa yatık olduğu görülmektedir. Tüm kurutma yöntemlerinde ölçülen renk değerlerinin frekans dağılımları Şekil 4'de verilmiştir.

Çizelge 6. Ölçülen renk değerlerine ait tanımlayıcı istatistik sonuçları

\begin{tabular}{|c|c|c|c|c|c|c|c|c|}
\hline $\begin{array}{l}\text { Kurutma } \\
\text { yöntemi }\end{array}$ & Renk değerleri & Ortalama & Std. Sapma & Maks. & Min. & Varyans & Kurtosis & Skewness \\
\hline \multirow{3}{*}{ Taze } & $\mathrm{L}$ & 21.69 & 3.48 & 26.13 & 12.40 & 12.09 & 2.57 & -1.49 \\
\hline & a & 13.33 & 3.91 & 22.68 & 8.90 & 15.29 & 0.82 & 1.08 \\
\hline & $\mathrm{b}$ & -0.65 & 1.11 & 1.90 & -1.83 & 1.24 & 0.23 & 0.96 \\
\hline \multirow{3}{*}{ Etüv } & $\mathrm{L}$ & 19.77 & 2.75 & 26.52 & 15.17 & 7.55 & 1.98 & 0.55 \\
\hline & a & 5.47 & 1.04 & 7.40 & 3.44 & 1.08 & 0.13 & 0.11 \\
\hline & $\mathrm{b}$ & -3.96 & 0.78 & -2.52 & -4.78 & 0.61 & -0.54 & 0.85 \\
\hline \multirow{3}{*}{ Mikrodalga } & $\mathrm{L}$ & 28.64 & 1.64 & 32.88 & 25.77 & 2.69 & 2.50 & 1.04 \\
\hline & $\mathrm{a}$ & 7.88 & 1.56 & 11.57 & 5.73 & 2.42 & 0.87 & 1.08 \\
\hline & $\mathrm{b}$ & -0.50 & 1.46 & 3.49 & -1.98 & 2.12 & 3.03 & 1.59 \\
\hline \multirow{3}{*}{ Güneş } & $\mathrm{L}$ & 26.92 & 3.12 & 30.16 & 19.51 & 9.77 & 3.14 & -1.97 \\
\hline & $\mathrm{a}$ & 4.29 & 0.57 & 5.47 & 3.18 & 0.32 & 1.86 & 0.77 \\
\hline & b & -3.70 & 0.38 & -2.95 & -4.28 & 0.15 & -0.61 & 0.23 \\
\hline \multirow{3}{*}{ Gölge } & $\mathrm{L}$ & 28.03 & 1.61 & 30.15 & 25.55 & 2.59 & -1.52 & -0.19 \\
\hline & a & 4.51 & 0.45 & 5.46 & 3.91 & 0.20 & -0.13 & 0.69 \\
\hline & b & -2.87 & 0.53 & -1.87 & -3.76 & 0.28 & -0.63 & 0.31 \\
\hline
\end{tabular}

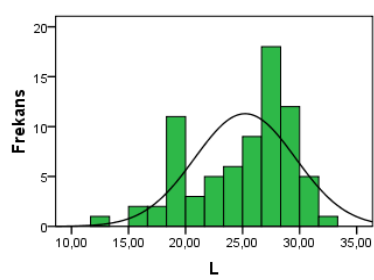

a

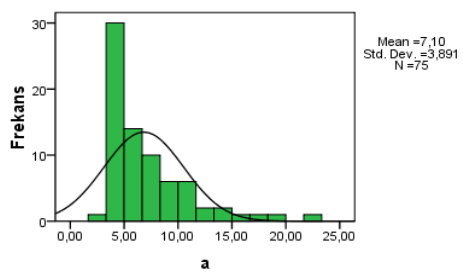

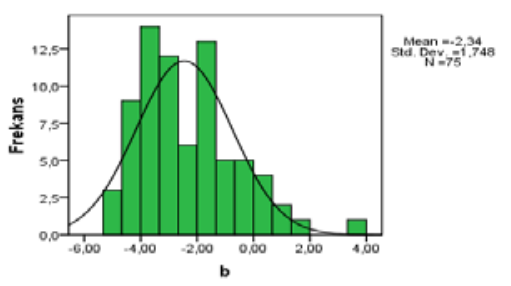

Şekil 4. Taze ve kurutulmuş örneklere ait ölçülen renk değerlerinin frekans dağılımı

Çizelge 7. Ölçülen ve hesaplanan renk değerlerine ait Duncan test sonuçları

\begin{tabular}{|c|c|c|c|c|c|c|c|c|}
\hline Kurutma yöntemi & $\mathrm{L}$ & $\mathrm{a}$ & $\mathrm{b}$ & $\mathrm{C}$ & $\mathrm{h}^{\circ}$ & $a / b$ & $\Delta \mathrm{E}$ & $\mathrm{BI}$ \\
\hline Taze & $21.69 \mathrm{~b}$ & $13.33 a$ & $-0.65 a$ & $13.40 \mathrm{a}$ & $-2.79 a$ & - & - & - \\
\hline Etüv & $19.77 \mathrm{c}$ & $5.47 \mathrm{c}$ & $-3.96 c$ & $6.82 \mathrm{bc}$ & $-35.90 b c$ & $-1.38 \mathrm{a}$ & $14.87 \mathrm{~b}$ & $0.09 c$ \\
\hline Mikrodalga & $28.64 a$ & $7.88 \mathrm{~b}$ & $-0.51 \mathrm{a}$ & $8.03 b$ & $-3.70 \mathrm{a}$ & $-15.45 b$ & $22.19 \mathrm{a}$ & $17.00 \mathrm{a}$ \\
\hline Güneş & $26.92 a$ & $4.29 c$ & $-3.70 c$ & $5.69 c$ & $-40.78 c$ & $-1.16 a$ & $22.08 a$ & $-1.78 c$ \\
\hline Gölge & $28.03 a$ & $4.51 \mathrm{c}$ & $-2.87 b$ & $5.37 \mathrm{c}$ & $-32.47 b$ & $-1.57 \mathrm{a}$ & $23.37 a$ & $1.47 \mathrm{~b}$ \\
\hline
\end{tabular}

İstatistiksel açıdan fark $(p<0.05)$ önem seviyesine göre önemlidir. 
Şekil 4'e göre, ölçülen tüm L parlaklık değerlerinin frekans dağılımı yoğun olarak 25-30 arasında değiştiği, a değerinin 5 civarlarında ve b değerinin ise yoğun olarak -4 ile -2 aralığında değiștiği görülmektedir. Taze ve kurutulmuş tüm örneklerin ortalama parlaklık değerinin 25.01, ortalama kırmızılık değerinin 7.10 ve ortalama sarılık değerinin ise -2.34 olduğu belirlenmiştir.

Taze ve kurutulan tüm örneklere ait renk değerlerinin istatistiksel açıdan birbirleri arasında farkın $(p<0.05)$ olup olmadığı belirlemek için Duncan testine tabi tutulmuş ve sonuçlar Çizelge 7'de verilmiştir.

Çizelge 7'ye göre, kurutulmuş örneklerin parlaklık ve kırmızılık değerlerinin tazeye göre istatistiksel açıdan birbirileri arasındaki farkın önemli olduğu görülürken, sarılık değerine göre ise sadece mikrodalga ile kurutulmuş örnekler arasında farkın önemli olmadığı görülmektedir. Kurutulmuş meyveler kroma kriteri açısında tazeye göre kıyaslandığında istatistiksel açıdan farkın önemli olduğu ancak mikrodalgada kurutulan ürünler hue değeri açısından tazeye göre klyaslandığında istatistiksel açıdan önemli bir farklılığın olmadığı tespit edilmiştir. Bununla beraber en az toplam renk değișiminin olduğu yöntemler arasında arasında, mikrodalgada kurutulan ürünlerin olduğu görülmüştür.

Bulgular ışığında mikrodalgada kurutulan mahlep meyvelerinin renk kriterleri açısından değerlendirildiğinde diğer yöntemlerden daha kaliteli sonuçlar alındığı tespit edilmiştir. Ölçülerek belirlenen renk kriterleri nihai ürünün renk kalitesi hakkında net bilgi vermesi zordur. $\mathrm{Bu}$ sebeple hesaplanarak belirlenen renk değerlerinin tüketici albenisi açısından kurutulmuş ürünün renginin değişimini, tonunu vb. kıyaslama kriterlerine göre, daha kolay yorumlayabilmektedir. Kroma değeri açısından kurutulmuş örnekler tazelerine göre klyaslandığında mikrodalga kurutma yönteminin daha daha uygun olduğu istatistiksel $(p<0.05)$ açıdan tespit edilmiştir. Kırmızılaşma ve toplam renk değişim kriterleri bir arada değerlendirildiğin de ise kurutulmuş örnekler arasında taze en yakın yöntemin yine mikrodalga olduğu görülmektedir (Çizelge 7). Kroma ve toplam renk değişim değerlerinin mikrodalga kurutma yönteminde tazeye daha yakın olmasını, bu yöntemde kuruma süresinin daha kısa olmasından dolayı ürün ısıya daha maruz kalmış ve renk pigmentleri daha az parçalanmasından kaynaklandığı düşünülmektedir. Kırmızılașma indeksinin yüksek olmasının durumu ise hem mikrodalga kurutma yönteminin belirtilen avantajinın etkisi hem de kurutma ile beraber kırmızı renk pigmentinin daha az parçalanması ve yoğunluğunun artmasından kaynaklandığ düşünülmektedir. Ayrıca kahverengileşme indeks değerinin mikrodalga kurutma yönteminde, diğer yöntemlere göre daha yüksek olmasının sebebinin de yine aynı nedenden kaynaklandı̆̆ düşünülmektedir. Literatürde mahlep meyvesinin özelliklerine benzer olarak kiraz meyvesini sıcak havalı bir kurutucuda farklı sıcaklıklarda kuruttuklarında son ürünün $L$ değerinin tazeye göre arttığı a ve b değerlerinin ise tazeye göre azaldığ görülmüştür (Altıok ve Otağ, 2019). Farklı kurutma yöntemlerinin karayemiş meyvesinin $L, a, b$ ve $C$ renk değerlerine olan etkilerinin istatistiksel açıdan $(p<0.05)$ önemli olduğunu ifade etmişler (Çelik ve ark., 2019). Benzer sonuçlar, Gümüşay ve Yalçın (2019) çalışmalarında da rastlanmaktadır.

Renk değerlerinin birbirini etkileme dereceleri (r) ve bu durumun istatistiksel açıdan önem seviyeleri ( $\left.{ }^{*} p<0.05 v e^{* *} p<0.01\right)$ Çizelge 8'de verilmiştir.

Çizelge 8. Renk değerlerine ait pearson test sonuçları

\begin{tabular}{|c|c|c|c|c|c|c|c|c|}
\hline Renk değerleri & $\mathrm{L}$ & $\mathrm{a}$ & $\mathrm{b}$ & $\mathrm{C}$ & $\mathrm{h}^{\circ}$ & $a / b$ & $\Delta \mathrm{E}$ & $\mathrm{BI}$ \\
\hline $\mathrm{L}$ & 1.00 & & & & & & & \\
\hline a & $-0.328^{* *}$ & 1.00 & & & & & & \\
\hline $\mathrm{b}$ & $0.233^{*}$ & $0.727^{* *}$ & 1.00 & & & & & \\
\hline $\mathrm{C}$ & $-0.402^{* *}$ & $0.991^{* *}$ & $0.657^{* *}$ & 1.00 & & & & \\
\hline $\mathrm{h}^{\circ}$ & 0.096 & $0.770^{* *}$ & $0.957^{* *}$ & $0.693^{* *}$ & 1.00 & & & \\
\hline$a / b$ & 0.114 & $0.752^{* *}$ & $0.938^{* *}$ & $0.667^{* *}$ & $0.993^{* *}$ & 1.00 & & \\
\hline$\Delta \mathrm{E}$ & $0.858^{* *}$ & -0.209 & 0.218 & $-0.260^{*}$ & 0.032 & 0.050 & 1.00 & \\
\hline BI & $-0.244^{*}$ & $0.966^{* *}$ & $0.790 * *$ & $0.946^{* *}$ & $0.800^{* *}$ & $0.782^{* *}$ & -0.043 & 1.00 \\
\hline
\end{tabular}

İstatistiksel açıdan fark $\left({ }^{*} p<0.05 v e^{* *} p<0.01\right)$ önem seviyesine göre önemlidir. 

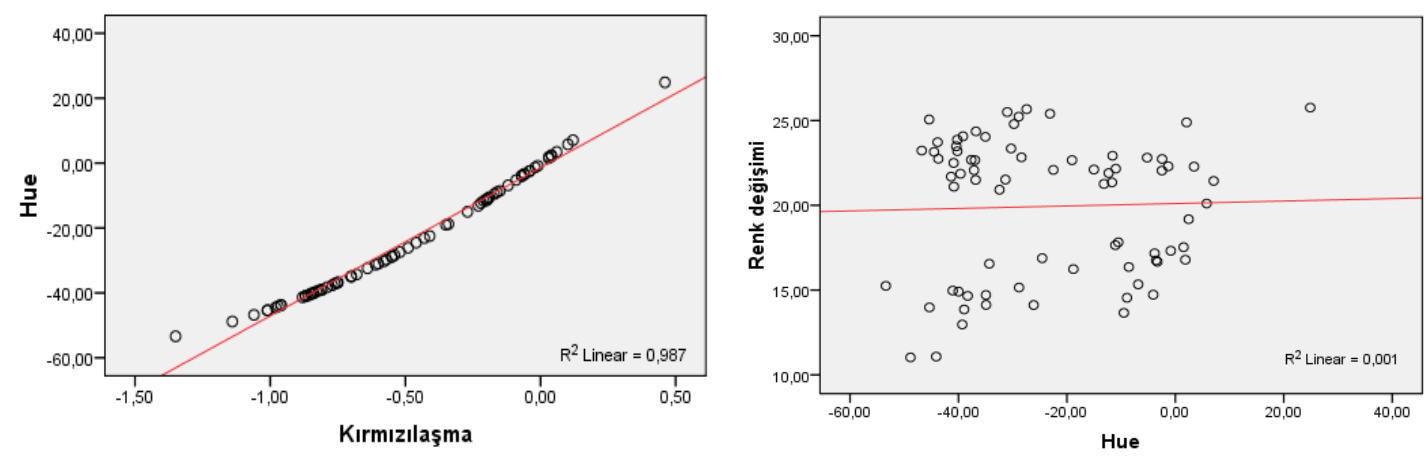

Şekil 5. En yüksek ve en zayıf korelasyonun olduğu renk değerlerinin dağılım grafiği

Çizelge 8'e göre, karşlık aynı renk değerleri hariç en yüksek korelasyon değerinin (r), hue ${ }^{\circ}$ ile kırmızılașma indeks değerleri arasında pozitif bir etkileşimin olduğu ve bu ilișkinin istatistiksel açıdan $p<0.01$ değerine göre önemli bulunduğu belirlenmiştir. En zayıf korelasyon değerinin (r) ise hue $^{\circ}$ ile toplam renk değişim değerleri arasında pozitif bir etkileşimin olduğu ve bu ilişkinin istatistiksel açıdan önemli olmadığı belirlenmiştir.

En yüksek ve en zayıf korelasyonun olduğu renk değerlerine ait dağılım grafiği Şekil 5'de verilmiştir.

Şekil 5'e göre, en yüksek korelasyonun olduğu dağılım verilerinden geçirilen doğrunun $\mathrm{R}^{2}$ değeri 0.967 olduğu ve yine en zayıf korelasyonun olduğu dağılım verilerine ait doğrunun $\mathrm{R}^{2}$ değerinin ise 0.001 olduğu tespit edilmiştir.

\section{Sonuc}

Uygulanan ince tabakalı kurutma modelleri arasında Alibaș ve Wang Sing modellerinin kuruma eğrilerini en iyi tahmin eden matematiksel eşitlikler olduğu tespit edilmiştir. Renk kriterleri açısından kurutulan örnekler tazeye göre klyaslandığında genel olarak mikrodalga ile kurutulan meyvelerin diğer yöntemlere göre daha kaliteli sonuçlar ortaya çıktığ görülmüştür.

Kurutma yöntemlerinin mahlebin kuruma özellikleri ve son kalite değerlerine önemli seviyede etkilediği anlaşıldığından dolayı daha detaylı bir şekilde kurutma koşullarının (ön uygulama, sıcaklık, kurutma yöntemi, hava hızı) değiştirilerek ve biyoaktif özelliklerinin de incelendiği multidisipliner çalışmaların yapılmasının gerekli olduğu düşünülmektedir.

\section{Kaynaklar}

Alibaş, İ. (2012). Asma Yaprağının (Vitis vinifera L.) Mikrodalga enerjisiyle kurutulması ve bazı kalite parametrelerinin belirlenmesi. Tarım Bilimleri Dergisi, 18, 43-53.

Altıok, D., \& Otağ, M.R. (2019). Assessment of physicochemical and bioactive properties of fresh and dried sweet cherry fruit. Karadeniz Fen Bilimleri Dergisi, 9 (1), 22-32.

Anonim., (2018). Mahlep. https,//tr.wikipedia.org/wiki/ Mahlep. (Erişim Tarihi, 08.08.2019).

Aydın, C., Öğüt, H., \& Konak, M. (2002). Some phsical properties of Turkish mahalep. Biosystem Engineering, 82(2), 231-234.

Bantle, M., Kopp, C. \& Claussen, I.C. (2019). Improved process control by surface temperature-controlled drying on the example of sweet potatoes. Proceedings of Eurodrying'2019 Torino, Italy, Temmuz, 10-12.

Başaran, A.A. (2012). Ülkemizdeki bitkisel ilaçlar ve ürünlerde yasal durum. MISED, 27-28, 22-26.

Blando, F., Albano, C., Liu, Y., Nicoletti, I., Corradini, D., Tommasi, N., Gerardi, C., Mita, G., \& Kitts, D.D. (2015). Polyphenolic composition and antioxidant activity of the under-utilised Prunus mahaleb L. fruit. Society of Chemical Industry, 96, 2641-2649 (DOI 10.1002/jsfa.7381).

Chen, H.H., Chiu, E.M., \& Huang, J.R. (1997). Color and gelforming properties of horse mackerel (Trachurus japonucus) as related to washing conditions. Journal of Food Science, 62, 985-991. 
Çelik, Ö.F., Demirkol, M., Durmuş, Y. \& Tarakçl, Z. (2019). Effects of drying method on the phenolics content and antioxidant activities of cherry laurel (Prunus laurocerasus L.). Journal of Food Measurement and Characterization.

Dak, M., Sagar, V.R., \& Jha, S.K. (2014). Shelf-life and kinetics of quality change of dried pomegranate arils in flexible packagig. Food Packaging and Shelf Life, 2 (1), 1-6.

Darıcl, M., Çelik, Z.D., \& Cabaroğlu, T. (2016). Mahlep șarabının aroma maddelerinin belirlenmesi. GIDA, 41 (2), 107-113, doi, 10.15237/gida.GD15064.

Duan, X., Liu, W.C., Ren, G.Y., \& Yang, X. (2017). Effects of different drying methods on the physical characteristics and flavor of dried hawthorns (Crataegus spp.). Drying Technology, 35 (11), 14121421.

Göztok, S.P., \& İçier, F. (2017). Karbon Fiber Destekli Kabin Kurutucuda Farklı Sicaklıklarda Elma Dilimlerinin Kurutulmasının İncelenmesi, Kurutma Karakteristikleri ve Performans Değerlendirmesi. Akademik Glda, 15(4), syf, 355-367, 2017.

Güleç, F., \& Özdemir, G.D.T. (2017). Karayemiş (Laurocerasus officinalis Roem.) meyvesinin kuruma karakteristiğinin incelenmesi. Akademik Ziraat Dergisi, 6 (1), 73-80.

Gümüşay, Ö.A. \& Yıldırım Yalçın, M. (2019). Effects of Freeze-Drying Process on Antioxidant and Some Physical Properties of Cherry Laurel and Kiwi Fruits. Akademik Gıda, 17 (1), 9-15, Doi, 10.24323/akademik-gida.543985.

Ieri, F., Pinelli, P., \& Romani, A. (2012). Simultaneous determination of anthocyanins, coumarins and phenolic acids in fruits, kernels and liqueur of Prunus mahaleb L.. Food Chem, 135, 2157-2162.

Kaya, A., \& Aydın, O. (2008). Experimental investigation of drying kinetics of Cherry Laurel. Journal of Food Process Engineering, 31 (3), 398-412.

Lewis, W.K. (1921). The rate of drying of solid materials. Industrial Engineering Chemistry, 13, 427-443.

Maskan, M. (2000). Microwave/air and microwave Ænish drying of banana. Journal of Food Engineering 44, 71-78.
McGuire, R.G. (1992). Reporting of objective color measurements. HortScience, 27, 1254-1255.

Midilli, A., Kücük, H., \& Yapar, Z. (2002). A new model for single-layer drying. Dry Technologies, 20 (7), syf. 1503-1513, 2002.

Moghadam, E.G., \& Khalighi, A. (2007). Relationship between vigor of Iranian Prunus mahaleb L. selected dwarf rootstocks and some morphological characters. Sci Hort, 111,209.

Njume, C., Afolayan, AJ., \& Ndip, R.N. (2009). An overview of antimicrobial resistance and the future of medicinal plants in the treatment of helicobacter pylori infections. Afr. J. Pharm. Pharmacol, 3, 685699.

Özturk, I., Karaman, S., Baslar, M., Cam, M., Calikan, O., Sagdic, O., \& Yalcin, H. (2014). Aroma, sugar and anthocyanin profile of fruit and seed of Mahalab (Prunus mahaleb L.), optimization of bioactive compounds extraction by simplex lattice mixture design. Food Anal Method, 7, 761-773.

Page, G. (1949). Factors influencing the maximum rates of air-drying shelled corn in thin layer. MS Thesis, Department of Mechanical Engineering, Purdue University (Unpublished), West Lafayette, IN, USA.

Plou, E., Lopez-Malo, A., Barbosa-Canovas, G.V., WeltiChanes, J., \& Swanson, B.G. (1999). Polyphenoloxidase activitiy and color of blanced and high hydrostatic pressure treated banana puree. Journal of Food Science, 64, 42-45.

Polatcl, H., \& Taşova, M. (2017). The effect on drying characteristics and colour values of hawthorn fruit of temperature controlled microwave drying method. Türk Tarım-Gıda Bilim ve Teknoloji Dergisi, 5 (10), 1130-1135.

Polatcı, H., \& Taşova, M. (2018). Mikrodalga firın ile kurutulan yenidünya (Eriobotrya japonica L.) meyvesinin kuruma kinetiği ve kalitesinin belirlenmesi”. Anadolu Tarım Bilimleri Dergisi, Cilt 33, Syf, 124-130, 2018.

Si, X., Chen, Q.Q., Bi, J.F., Wu, X.Y., Yi, J.Y., \& Zhou, L.Y. (2016). Comparison ofdifferent drying methods on the physical properties, bioactive compounds and antioxidant activity of raspberry powders. Journal of the Science of Food and Agriculture, 96, 20552062. 
Wang, C.Y., \& Singh, R. P. (1978). A single layer drying equation for rough rice. ASAE, 78-3001.
Yağcıoglu, A. (1999). Tarımsal ürünleri kurutma tekniği. Ege Üniversitesi Ziraat Fakültesi yayınları No, 536. Bornova, İzmir. 